\title{
Diffusion and Crystallization of Dichloromethane within the Pores of Amorphous Solid Water
}

Radha Gobinda Bhuin, Rabin Rajan J. Methikkalam, Soumabha Bag, and Thalappil Pradeep*

DST Unit of Nanoscience (DST UNS) and Thematic Unit of Excellence (TUE), Department of

Chemistry, Indian Institute of Technology Madras, Chennai 600 036, India

\author{
*Corresponding author: Fax: + 91-44 2257-0545 \\ *E-mail:pradeep@iitm.ac.in
}

\section{Supporting information 1:}

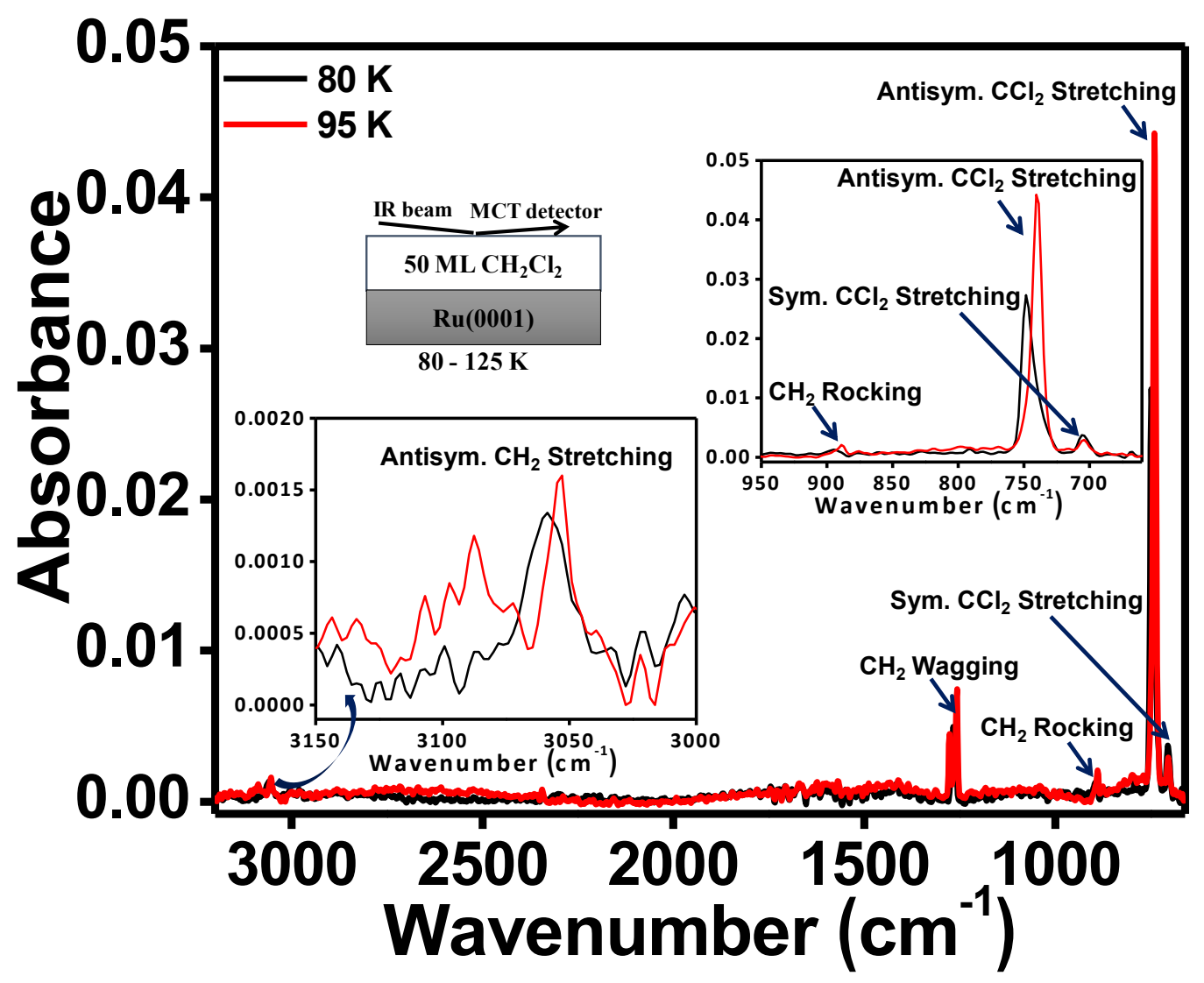

Figure S1. Temperature dependent RAIR spectra of $50 \mathrm{ML} \mathrm{CH}_{2} \mathrm{Cl}_{2} . \mathrm{CH}_{2} \mathrm{Cl}_{2}$ was deposited at $80 \mathrm{~K}$ on $\mathrm{Ru}(0001)$. Schematic of the experiment is shown in one inset and another inset shows the expanded view of different regions. 


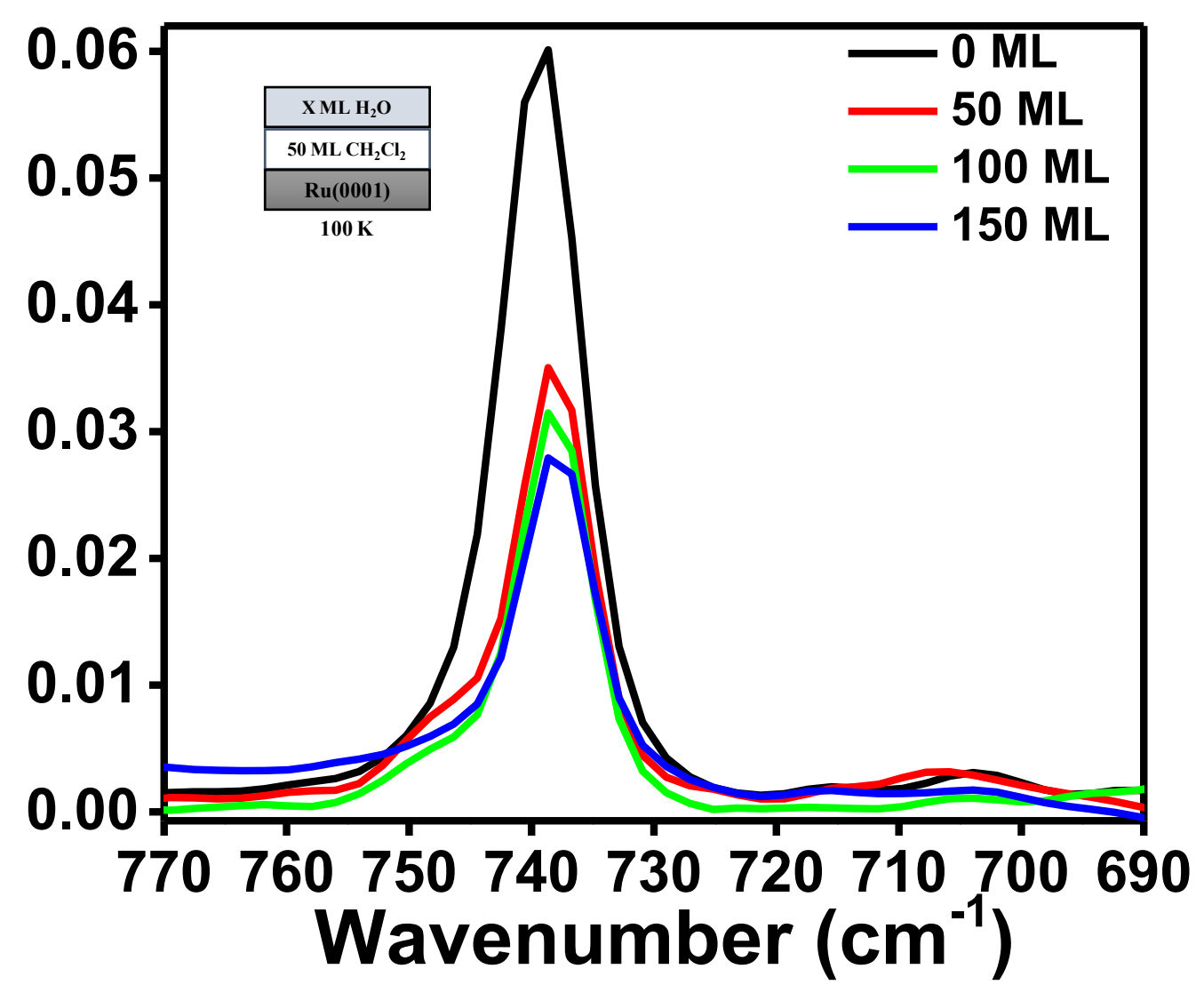

Figure S2. RAIR spectra of - $\mathrm{CCl}_{2}$ antisymmetric mode of $50 \mathrm{ML} \mathrm{CH}_{2} \mathrm{Cl}_{2}$ as a function of overlayer coverages of ASW at $100 \mathrm{~K}$. Inset shows the schematic of the surface. Both $\mathrm{CH}_{2} \mathrm{Cl}_{2}$ and $\mathrm{H}_{2} \mathrm{O}$ were deposited at $80 \mathrm{~K}$ on $\mathrm{Ru}(0001)$ surface. 